\title{
Histoire et civilisation du monde byzantin,
} 1975-2001

\section{Gilbert Dagron}

\section{(2) OpenEdition}

1 Journals

Édition électronique

URL : https://journals.openedition.org/annuaire-cdf/1069

DOI : 10.4000/annuaire-cdf.1069

ISBN : 978-2-7226-0325-7

ISSN : 2109-9227

Éditeur

Collège de France

Édition imprimée

Date de publication : 1 avril 2013

Pagination : 783-787

ISBN : 978-2-7226-0198-7

ISSN : 0069-5580

\section{Référence électronique}

Gilbert Dagron, « Histoire et civilisation du monde byzantin, 1975-2001 », L'annuaire du Collège de

France [En ligne], 112 | 2013, mis en ligne le 22 novembre 2013, consulté le 22 août 2022. URL : http:// journals.openedition.org/annuaire-cdf/1069; DOI : https://doi.org/10.4000/annuaire-cdf.1069 


\section{EXPOSITIONS}

Reconstitution de la Grotte de Lascaux, Les Francs-Bourgeois, ouverture 3 décembre 2011 (allocution).

Paléospace l'Odyssée, Villers-sur-mer, Inauguration officielle, 15 octobre 2011 (parrainage).

Exhibitions, l'invention du sauvage, 1880-1930, Fondation Lilian Thuram, Musée du quai Branly, inauguration 28 novembre 2011 (parrainage).

Sur la trace des Dinosaures polaires, voyage aux confins de la Sibérie, Paleopolis, Gannat, avril 2012 (président du Comité scientifique).

L'identité retrouvée; les reconstructions anatomiques d'Elisabeth Daynès, Musée départemental de Préhistoire d'Ile de France, Nemours, octobre 2011-septembre 2012 (catalogue).

Création du Jeongok prehistory Museum (Corée du Sud), inauguration, 2011 (Architectes Anouk Legendre, Nicolas Desmazières, paléontologue délégué Fabrice Demeter, direction Yves Coppens, 2007-2011).

En pays fali, un ethnologue charentais au Nord Cameroun, Musée d'Angoulême juin 2012 (catalogue et ouverture).

The Cradle of Humanity, Museum of Human Evolution (Burgos), Museum of Dar-esSalaam (Tanzanie), Institute of Evolution in Africa (IDEA), commissaires Manuel Dominguez Rodrigo et Enrique Baquedano Pérez, 2012 (participation au catalogue).

\section{DISTINCTIONS}

Lauréat de l'Excellence française 2011 (Hôtel de la Marine, 24 novembre 2011).

Médaille de la ville de Lyon (Lyon, 25 novembre 2011).

\section{Gilbert DAGRON, membre de l'Institut (Académie des inscriptions et belles-lettres) \\ Histoire et civilisation du monde byzantin, 1975-2001}

\section{Publications}

Dagron G., L'Hippodrome de Constantinople. Jeux, peuple et politique, Gallimard, coll. « Bibliothèque des Histoires », Paris, 2011, 439 p.

Dagron G., Idées byzantines I-II, Centre d'histoire et civilisation de Byzance du Collège de France, coll. «Bilans de recherche », 8, tomes I et II, Paris, 2012, 821 p.

\section{ACTIVITÉS RÉCENTES}

Participation au colloque tenu à l'École normale supérieure en hommage à Jacqueline de Romilly, le 27 octobre 2011 : «Grèce, hellénisme, romanité ».

Émission à France Culture, le 2 janvier 2012, à l'occasion de la publication de mon livre L'Hippodrome de Constantinople. Jeux, peuple et politique.

Réunions diverses au Centre d'histoire et civilisation de Byzance en vue de la préparation de manuscrits. 